Article

\title{
Adaptive Control of HVDC Links for Frequency Stability Enhancement in Low-Inertia Systems
}

\author{
Jelena Stojković ${ }^{1, *(\mathbb{D})}$, Aleksandra Lekić ${ }^{2, *}$ and Predrag Stefanov ${ }^{1}$ \\ 1 School of Electrical Engineering, University of Belgrade, 11000 Belgrade, Serbia; stefanov@etf.bg.ac.rs \\ 2 Faculty of Electrical Engineering, Mathematics and Computer Science, Delft University of Technology, \\ 2629 Delft, The Netherlands \\ * Correspondence: jstojkovic@etf.bg.ac.rs (J.S.); A.Lekic@tudelft.nl (A.L.)
}

Received: 15 October 2020; Accepted: 20 November 2020; Published: 24 November 2020

\begin{abstract}
Decarbonization of power systems has put Renewable Energy Sources (RES) at the forefront when it comes to electric power generation. The increasing shares of converter-connected renewable generation cause a decrease of the rotational inertia of the Electric Power System (EPS), and consequently deteriorate the system capability to withstand large load-generation imbalances. Low-inertia systems are subjected to fast and large frequency changes in case of in-feed loss, where the traditional primary frequency control is not sufficient to preserve the frequency stability and to maintain the frequency above the critical value. One possible solution to this rising problem is seen in Fast Frequency Response (FFR) provided by the High-Voltage Direct-Current (HVDC)-based systems. This paper presents the adaptive FFR control of HVDC-based systems for frequency stability enhancement in the low-inertia system. The EPS is considered as a "black box" and the HVDC response is determined only using the locally measured frequency change. Sliding Mode Control (SMC) of the Modular Multilevel Converter (MMC) was developed and demonstrated to provide faster and more appropriate frequency response compared to the PI controller. The described adaptive HVDC control considers the size of disturbance and the inertia of the power system, and it is verified by simulations on the IEEE 39 bus test system implemented in MATLAB/Simulink for different system configurations and different sizes of disturbance.
\end{abstract}

Keywords: frequency control; low-inertia power systems; HVDC-based power system; modular multilevel converter

\section{Introduction}

With the rising penetration of converter-connected renewable generation and phasing-out of coal generation plants that are directly connected to the power grid, the rotational inertia of the AC Electrical Power System (EPS) is decreasing. The reduction of the rotational inertia in the power system goes hand-in-hand with the decarbonization of the EPS. Rotational inertia is a key indicator of a power system's ability to withstand disturbances and determines how fast the system frequency will change in the response to a disturbance. The maximum Rate of Change of Frequency (RoCoF) is inversely proportional to the system inertia, and low-inertia systems are subjected to large frequency deviations in the event of outages that can lead to further cascading outages. Frequency stability would become an even more critical issue with the growing integration of solar and wind generation capacities that do not contribute to system rotational inertia. Traditional frequency control is not sufficiently fast to prevent frequency drop under permitted limits and Transmission System Operators (TSOs) are forced to increase the system's inertia or reduce the size of the single largest loss of in-feed.

Frequency stability is particularly endangered in EPSs that have a high share of converterconnected renewables and have no AC interconnections with other EPSs. Those power systems do not 
have access to the synchronous inertia of the other power systems. Thus, they face rapid changes in frequency and high values of RoCoF, even in situations when there is a relatively low penetration rate of renewable generation. EirGrid (TSO for Ireland) and SONI (TSO for Northern Ireland) initiated a series of studies designed to examine the technical challenges involved in achieving ambitious renewable energy targets $[1,2]$. The studies found that it was necessary to limit the amount of nonsynchronous generation units to $50 \%$ in order to maintain system security in the event of a disturbance, unless RoCoF relays on wind farms and other generators were disabled or adapted [1]. The National Grid (UK TSO) detected a decline in synchronous inertia and launched numerous investigations to tackle this problem [3,4]. The high value of RoCoF has been identified as an immediate challenge since it can cause cascading tripping of generators [3]. A clear example happened in August 2019, when the UK power system experienced a big power cut as a result of outages of 2 generators while most of the power consumption was fed by wind generation [5]. All these publications have identified frequency stability as a rising problem in low-inertia systems.

In low-inertia systems, it takes less time for frequencies to reach a critical value after a disturbance and it is necessary to consider a faster frequency control that will respond before the primary control. It should be fast enough to prevent the frequency drop below the permitted limit. Most of the systems that are particularly vulnerable due to low inertia in terms of frequency stability are poorly connected to other systems or are connected via High-Voltage Direct-Current (HVDC) lines. The HVDC lines-although they disconnect systems in terms of inertia sharing-have great capabilities in terms of fast frequency regulation [6-9]. They can quickly change output active power and provide a Fast Frequency Response (FFR) service, and also represent a cost-effective tool for sustaining frequency stability $[10,11]$. The authors of [10] evaluated the potential economic benefits of utilizing the Emergency Power Control functionality of HVDC lines for the provision of fast reserves as a complement to traditional frequency control. Their findings suggest that the cost of security for Nordic TSOs could be reduced by 70\% if HVDC links are used for fast frequency support. The results from [11] showed that frequency-response-reserves-sharing through a Voltage Source Converter (VSC)-based HVDC link can greatly help the frequency stability of interconnection after the in-feed loss while reducing the financial loss of disturbed interconnection during the event.

Droop control is a typical control scheme for HVDC-based frequency support that has been proposed multiple times [12-15]. Although it is simple and can be easily implemented, it does not effectively utilize the fast response capabilities of HVDC-based systems, since the output active power increases gradually. An improved droop control strategy of HVDC interconnections based on the slope control of the DC voltage and AC frequency was introduced in [16], but did not include detailed modeling of grid components and generators that can influence the frequency response. Results from [17] showed that droop frequency-based FFR from HVDC outperformed the control method based on ramp power injections and frequency triggering activation for the Nordic power system. However, results might be different if the authors consider RoCoF triggering activation, as a frequency first time-derivative is a faster indicator of critical disturbance and potential frequency collapse. In [18], a methodology for tuning a supervisory and frequency-response outer control loop of a multiterminal HVDC grid was designed, but provides frequency support only during over-frequency events that are less critical compared to under-frequency events in terms of frequency stability.

The HVDC-based power system incorporates power electronic converters used for conversion between AC and DC power grids [19]. Power converters can be implemented as Line Commutated Converters (LCCs) or Voltage Source Converters (VSCs). The two common versions of the VSC are two-level converters and Modular Multilevel Converters (MMCs). Since MMCs offer high modularity of applied controls and full scalability [20], we used them as a model in our work. Sliding mode control is a known nonlinear controlling method used in the switching systems. It has been introduced as a controlling method design for the MMC's different inner and/or outer controlling loops. Reference [21] provides an application of the discrete sliding mode controller for balancing capacitor voltages of switching modules. In [22], the application of the sliding mode control for controlling of the active and 
reactive powers was demonstrated. Some works have discussed suppressing the MMC's circulating current [23].

This paper presents an adaptive control for fast frequency support for HVDC-based power systems that considers the magnitude of disturbance and the system inertia. The proposed control consists of two main stages. In the first stage, HVDC response is constant and triggered by locally measured $\mathrm{RoCoF}$ as a disturbance indicator, and the size of the disturbance is estimated using the generator swing equation and frequency response. In the second stage, the HVDC response is adapted to the estimated size of disturbance, providing more adequate support to preserve frequency stability during emergency conditions. HVDC is connected to an AC grid through an MMC inverter, which is controlled using several inner and outer controlling loop controllers. Two power controlling methods are proposed: one employing PI active and reactive power controller, and the other with an integral sliding mode controller (ISMC) for the active and reactive power. The proposed frequency adaptive control is implemented in MATLAB/Simulink and verified through simulations of the IEEE 39 bus test system. The novelty of the proposed solution lies in the fact that even though the controller does not have information about the power system and the disturbance, it effectively estimates and deploys sufficient reserves to ensure system stability. The proposed method fully exploits the fast, dynamic capabilities of HVDC converters (providing fast, almost instantaneous, step increase of output active power), contrary to the grid-forming controls where the active power injection is gradually increasing [24-26]. This way, the presented method enhances the frequency stability as much as possible and it is the most important advantage of the presented method over the grid-forming controls.

The paper is organized as follows. Theoretical foundation and mathematical model of the proposed adaptive control is provided in Section 2. In Section 3, a description of the used MMC topology including its modeling and controller designs is given. Section 4 briefly describes case studies for validation of the proposed control method with simulation results followed by the discussion. Finally, in Section 5, some closing remarks are given.

\section{Adaptive FFR Control}

The first step of FFR control for the HVDC system is the disturbance event detection. The RoCoF is largest immediately after the disturbance and it can be used as a fast indicator of potentially dangerous system conditions. RoCoF, as a first time derivative of frequency, has a predictive capability and enables fast identification of frequency collapse. If the locally measured RoCoF value is above the specified threshold level and the frequency is below the specified value, MMC would provide frequency response. When the disturbance event is detected, the HVDC response in the first step is constant and equal to a predefined value. The first step of HVDC response is determined by offline analysis, based on an assessment of the configuration of the system and its inertia in a day-ahead scheduling plan.

The maximum RoCoF value depends on the magnitude of disturbance and the rotational inertia of the system. In low-inertia systems, even small disturbances (loss of in-feed) can cause high RoCoF values, and the RoCoF-based fast frequency support can provide an unnecessarily large response to prevent frequency collapse. This causes undesired costs and potential oscillatory issues and there is a need for adaptive FFR control that considers the size of disturbance. The size of the disturbance is estimated in the second stage of the control method using the classical swing equation:

$$
\frac{d f}{d t}=\frac{f_{o}}{2 H S_{b}}\left(-k_{D} \Delta f_{0}+\Delta P\right),
$$

where $f_{0}$ corresponds to the nominal frequency, $H$ represents the inertia constant, and $S_{b}$ is the generation power in the system. Constant $k_{D}$ is the reciprocal value of the load damping coefficient that models the sensitivity of load to frequency change and the disturbance $\Delta P$ is defined as the difference between the total generation power and the total system load. The traditional primary frequency response is neglected since it is usually activated within 5 to $10 \mathrm{~s}$ after the frequency 
deviation is measured because the generators providing this service need time to ramp up and increase their power output. The time interval of the interest for FFR is within $2 \mathrm{~s}$ after a disturbance.

The basic shape of frequency response before the HVDC response can be easily obtained from (1):

$$
\Delta f_{1}(t)=\frac{\Delta P}{k_{D}}\left(1-\exp \left(-\frac{k_{D} f_{0} t}{2 H S_{b}}\right)\right)
$$

while the frequency after the initial HVDC response $\Delta P_{H V D C}$ changes according to

$$
\Delta f_{2}(t)=\Delta f_{*}+\frac{\Delta P-\Delta P_{H V D C}-k_{D} \Delta f_{*}}{k_{D}}\left(1-\exp \left(-\frac{k_{D} f_{0}\left(t-t_{1}\right)}{2 H S_{b}}\right)\right),
$$

where $t_{1}$ is the moment of the initial HVDC response and $\Delta f_{*}$ corresponds to the frequency deviation in the moment of initial HVDC response.

The difference between the two frequency values on time interval $\Delta t$ before the initial HVDC response is

$$
d \Delta f_{1}(t)=\Delta f_{1}(t+\Delta t)-\Delta f_{1}(t)=\frac{\Delta P}{k_{D}}(\exp (-\Delta t)-1) \exp \left(-\frac{k_{D} f_{0} t}{2 H S_{b}}\right) ;
$$

and after the HVDC response, it is

$$
d \Delta f_{2}(t)=\Delta f_{2}(t+\Delta t)-\Delta f_{2}(t)=\frac{\Delta P-\Delta P_{H V D C}-k_{D} \Delta f_{*}}{k_{D}}(\exp (-\Delta t)-1) \exp \left(-\frac{k_{D} f_{0}\left(t-t_{1}\right)}{2 H S_{b}}\right) .
$$

Taking the assumption that load reduction due to self-regulation is not significant in relation to the magnitude of the disturbance and the response of HVDC in the first step, the magnitude of the disturbance can be approximately estimated. This assumption is justified because the change in load is proportional to the deviation of the frequency that is relatively small shortly after the disturbance. The size of the disturbance can be estimated using Equations (4) and (5):

$$
\Delta P=\Delta P_{H V D C} \frac{d \Delta f_{1}}{d \Delta f_{1}-d \Delta f_{2}} .
$$

In addition, primary controllers and the responses of other electronic devices are omitted which introduces an error in the estimation of the disturbance size. The proposed control aims to roughly estimate the disturbance size, fast but not that accurate. Therefore, using the simple relations and neglecting the response of other devices is justified.

It should be noted that the first stage of the HVDC response $\Delta P_{H V D C}$ should be ideally determined by offline analysis, based on an assessment of the configuration of the system and its inertia in a day-ahead scheduling plan. However, the power system is considered as a "black box", and if there is no such information, it can be arbitrarily adopted as it is done in the simulations. The value of the first stage of HVDC response $\Delta P_{H V D C}$ is not of much importance since it is used only for the estimation of the disturbance size. The adaptive stage of the HVDC response would provide an adequate response considering the disturbance size and system inertia. The instant when the first stage of HVDC response is triggered can be adopted arbitrarily and does not affect the results of the estimated size of the disturbance. In terms of the frequency stability, it should be as soon as possible. In simulations, the first stage of HVDC response is triggered $0.5 \mathrm{~s}$ after the disturbance happens based on the assumption that it takes around $200 \mathrm{~ms}$ to detect the disturbance and $300 \mathrm{~ms}$ to calculate the frequency slope. The adopted assumptions are based on standards for measuring devices.

The second step of HVDC response $\triangle P_{H V D C 2}$ is calculated based on the estimated size of disturbance and initial RoCoF value that is inversely proportional to system inertia:

$$
\Delta P_{H V D C 2}=\triangle P \operatorname{RoCoF}(0) \text {. }
$$


In this way, the second step of HVDC response would be larger for the same size disturbance in a low-inertia system than in the high-inertia system, which is more adequate in terms of frequency stability. It should be emphasized that the aim of the proposed control actions is not to accurately assess the size of the disturbance and adapt the HVDC response accordingly, but to provide a sufficiently fast, adequate response so that the frequency remains within the predicted limits. The second step of HVDC response eliminates the risk that the initial response would be too large/small which, in the case of single-stage control, must certainly occur in the event of various outages in the system.

The starting moment of the second stage is chosen arbitrarily. It is should be as soon as possible since the prior activation supports the frequency stability more effectively. It is taken that the first stage of HVDC response is dispatched $0.5 \mathrm{~s}$ after the disturbance, and the second stage $0.5 \mathrm{~s}$ after the first one. Considering that the measuring device will experience frequency spikes immediately after the disturbance that can affect the punctuality of obtained frequency values, the calculation of the slope of the frequency response is done on the time interval from $0.2 \mathrm{~s}$ to $0.5 \mathrm{~s}$ after the disturbance. It is considered that $0.2 \mathrm{~s}$ after the disturbance/initial HVDC response frequency transients are negligible. The duration of the second stage should be coordinated with the primary control and it is out of a scope of this aliases.

It should be pointed out that the aim of the second stage of HVDC response is not to provide the optimal response to the disturbance, but to provide a more adequate response compared to the first stage considering the different sizes of disturbances and the system inertia. The power system is considered as a "black box", only the locally measured frequency change is acquirable, and therefore the simplest correlation between the disturbance size and initial RoCoF value is assumed. Ideally, the exact correlation should be carefully investigated based on system parameters. The coefficient equal to 1 is subjectively chosen, and it is speculative. However, it gives acceptable results.

The proposed control is also efficient to limit the increase in frequency (loss of load), but due to less criticality, it is not analyzed in detail in the paper.

A flow chart of the power system's response algorithm is shown in Figure 1.

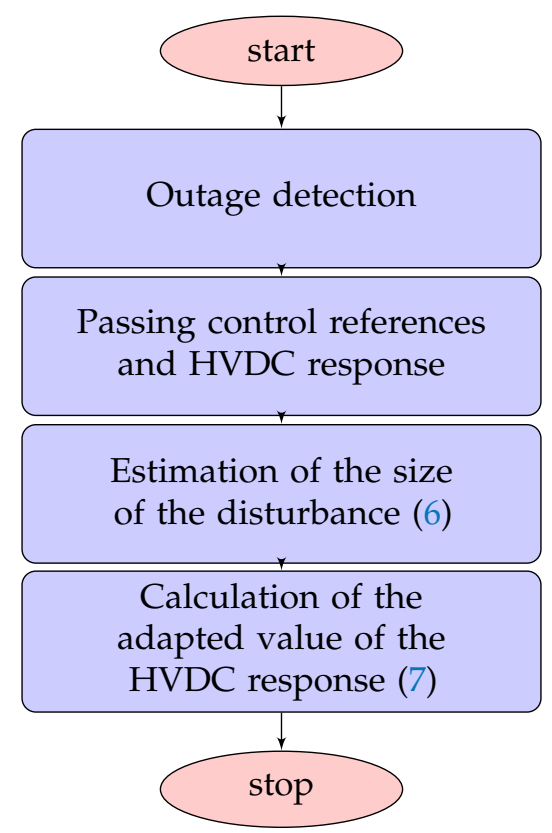

Figure 1. Flow chart of the power system's response algorithm. HVDC-High-Voltage Direct-Current.

\section{MMC Modeling}

In this work, an MMC represents an inverter that should answer to the AC grid requirements by providing sufficient active power and by maintaining reactive power at a stable value. It consists of 3 legs with 2 arms each. The arm has $N$ switching modules realized as a half-bridge type. 
In Figure 2, one leg of the MMC is depicted, where superscript $j \in\{a, b, c\} . v_{j}^{G}$ is denotes AC voltage; $L_{r}$ and $R_{r}$ are reactor inductance and resistance, respectively; and $R_{a r m}$ and $L_{a r m}$ represent equivalent arm resistance and inductance, respectively. The equivalent capacitance of one arm is denoted as $C_{a r m}=\frac{C}{N}$, where $C$ is a capacitance used in the submodule. It is assumed that the grid is balanced, has a symmetric monopolar configuration, and the voltage at the HVDC side is equal $v_{d c}$.

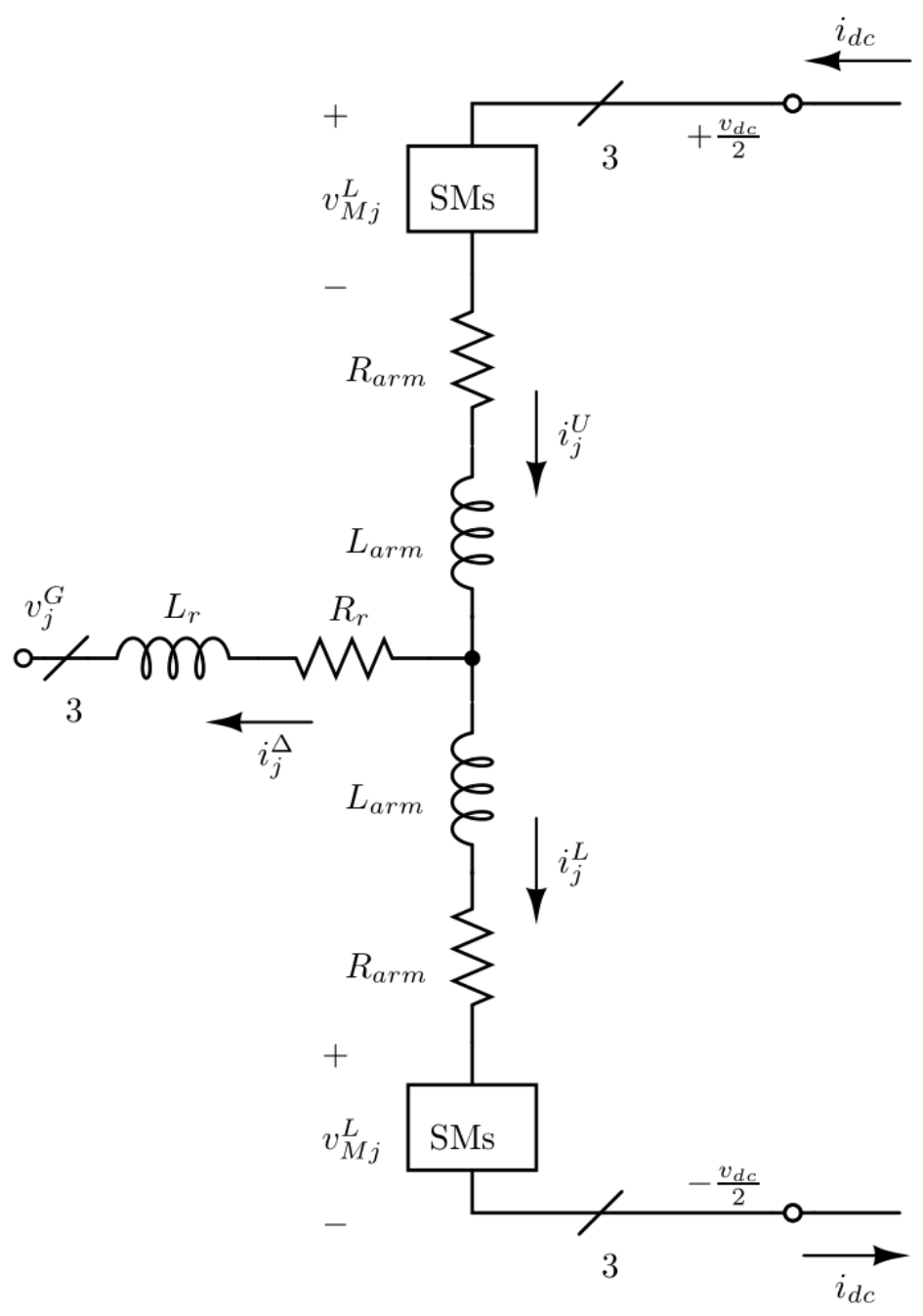

Figure 2. Modular Multilevel Converter (MMC) model.

To obtain results with as much complexity as possible, we considered a model that incorporates 3 harmonics in the simple manner. This MMC model was first presented in [27], and it provides a linear steady-state solution. This model has been shown to be suitable for incorporation of the multiple controlling loops one-by-one. The controlling loops' implementations are summarized in [28]. In our work, we have considered the complete MMC model from [27], which incorporates frequencies $\omega$ and $3 \omega$ for the $\Delta$ components and dc and $-2 \omega$ for $\Sigma$ components.

Submodules are represented with their averaged equivalent, and thus, the following equations for the voltage and current can be written for the upper and lower arms:

$$
v_{M j}^{U, L}=m_{j}^{U, L} v_{C j}^{U, L}, \quad i_{M j}^{U, L}=m_{j}^{U, L} i_{j}^{U, L},
$$


where $m_{j}^{U, L}$ are the corresponding upper and lower arm insertion indices. The converter model is developed by following the methodology reported in [27,28]. Using the $\Sigma-\Delta$ nomenclature, the variables in the upper and lower converter arms can be determined as

$$
\begin{aligned}
i_{j}^{\Delta} & =i_{j}^{U}-i_{j}^{L}, \quad i_{j}^{\Sigma}=\frac{i_{j}^{U}+i_{j}^{L}}{2}, \\
v_{C j}^{\Delta} & =\frac{v_{C j}^{U}-v_{C j}^{L}}{2}, \quad v_{C j}^{\Sigma}=\frac{v_{C j}^{U}+v_{C j}^{L}}{2}, \\
m_{j}^{\Delta} & =m_{j}^{U}-m_{j}^{L}, \quad m_{j}^{\Sigma}=m_{j}^{U}+m_{j}^{L}, \\
v_{M j}^{\Delta} & =\frac{-v_{M j}^{U}+v_{M j}^{L}}{2}=-\frac{m_{j}^{\Delta} v_{C j}^{\Sigma}+m_{j}^{\Sigma} v_{C j}^{\Delta}}{2}, \\
v_{M j}^{\Sigma} & =\frac{v_{M j}^{U}+v_{M j}^{L}}{2}=\frac{m_{j}^{\Sigma} v_{C j}^{\Sigma}+m_{j}^{\Delta} v_{C j}^{\Delta}}{2} .
\end{aligned}
$$

From the previous equations, it is easy to determine output $\mathrm{AC}$ current as being $i_{j}^{\Delta}$. After transformation in dqz-frame, the MMC is described using differential equations:

$$
\begin{aligned}
\dot{\overrightarrow{\boldsymbol{i}}}_{d q}^{\Delta} & =\frac{\overrightarrow{\boldsymbol{v}}_{M d q}^{\Delta}-\left(\omega L_{e q}^{a c} \mathbf{J}_{2}+R_{e q}^{a c} \mathbf{I}_{2}\right) \overrightarrow{\boldsymbol{i}}_{d q}^{\Delta}-\overrightarrow{\boldsymbol{v}}_{d q}^{G}}{L_{e q}^{a c}}, \\
\dot{\overrightarrow{\boldsymbol{i}}}_{d q}^{\Sigma} & =-\frac{\overrightarrow{\boldsymbol{v}}_{M d q}^{\Sigma}+\left(R_{a r m} \mathbf{I}_{2}-2 \omega L_{a r m} \mathbf{J}_{2}\right) \overrightarrow{\boldsymbol{i}}_{d q}^{\Sigma}}{L_{a r m}}, \\
\dot{i}_{z}^{\Sigma} & =\frac{v_{d c}}{2 L_{a r m}}-\frac{v_{M z}^{\Sigma}+R_{a r m} i_{z}^{\Sigma}}{L_{a r m}}, \\
\dot{\overrightarrow{\boldsymbol{v}}}_{C d q}^{\Delta} & =\frac{N}{2 C} \overrightarrow{\boldsymbol{i}}_{M d q}^{\Delta}-\omega \mathbf{J}_{2} \overrightarrow{\boldsymbol{v}}_{C d q}^{\Delta}, \\
\dot{\overrightarrow{\boldsymbol{v}}}_{C Z d q}^{\Delta} & =-\frac{N}{8 C} \Psi-3 \omega \mathbf{J}_{2} \overrightarrow{\boldsymbol{v}}_{C Z d q \prime}^{\Delta}, \\
\dot{\overrightarrow{\boldsymbol{v}}}_{C d q z}^{\Sigma} & =\frac{N}{2 C} \overrightarrow{\boldsymbol{i}}_{M d q z}^{\Sigma}+2 \omega \mathbf{J}_{3} \overrightarrow{\boldsymbol{v}}_{C d q z^{\prime}}^{\Sigma},
\end{aligned}
$$

where

$$
\begin{aligned}
& \overrightarrow{\boldsymbol{i}}_{M d q}^{\Delta}=\mathbf{P}_{\omega}(t)\left(\mathbf{P}_{-2 \omega}^{-1}(t) \overrightarrow{\boldsymbol{m}}_{d q z}^{\Sigma} \circ \frac{\mathbf{P}_{\omega}^{-1}(t) \overrightarrow{\boldsymbol{i}}_{d q z}^{\Delta}}{2}+\mathbf{P}_{\omega}^{-1}(t) \overrightarrow{\boldsymbol{m}}_{d q z}^{\Delta} \circ \mathbf{P}_{-2 \omega}^{-1}(t) \overrightarrow{\boldsymbol{i}}_{d q z}^{\Sigma}\right), \\
& \vec{i}_{M d q z}^{\Sigma}=\mathbf{P}_{-2 \omega}(t)\left(\mathbf{P}_{-2 \omega}^{-1}(t) \overrightarrow{\boldsymbol{m}}_{d q z}^{\Sigma} \circ \mathbf{P}_{-2 \omega}^{-1}(t) \vec{i}_{d q z}^{\Sigma}+\mathbf{P}_{\omega}^{-1}(t) \overrightarrow{\boldsymbol{m}}_{d q z}^{\Delta} \circ \mathbf{P}_{\omega}^{-1}(t) \frac{\overrightarrow{\boldsymbol{i}}_{d q z}^{\Delta}}{2}\right), \\
& \overrightarrow{\boldsymbol{v}}_{M d q z}^{\Delta}=-\frac{\mathbf{P}_{\omega}}{2}(t)\left(\mathbf{P}_{\omega}^{-1}(t) \overrightarrow{\boldsymbol{m}}_{d q z}^{\Delta} \circ \mathbf{P}_{-2 \omega}^{-1}(t) \overrightarrow{\boldsymbol{v}}_{C d q z}^{\Sigma}+\mathbf{P}_{-2 \omega}^{-1}(t) \overrightarrow{\boldsymbol{m}}_{d q z}^{\Sigma} \circ \mathbf{P}_{\omega}^{-1}(t) \overrightarrow{\boldsymbol{v}}_{C d q z}^{\Delta}\right), \\
& \overrightarrow{\boldsymbol{v}}_{M}^{\Sigma}=\frac{\mathbf{P}_{-2 \omega}(t)}{2}\left(\mathbf{P}_{\omega}^{-1}(t) \overrightarrow{\boldsymbol{m}}_{d q z}^{\Delta} \circ \mathbf{P}_{\omega}^{-1}(t) \overrightarrow{\boldsymbol{v}}_{C d q z}^{\Delta}+\mathbf{P}_{-2 \omega}^{-1}(t) \overrightarrow{\boldsymbol{m}}_{d q z}^{\Sigma} \circ \mathbf{P}_{-2 \omega}^{-1}(t) \overrightarrow{\boldsymbol{v}}_{C d q z}^{\Sigma}\right), \\
& \Psi=\left[\begin{array}{l}
i_{d}^{\Delta} m_{d}^{\Sigma}+2 i_{d}^{\Sigma} m_{d}^{\Delta}+i_{q}^{\Delta} m_{q}^{\Sigma}+2 i_{q}^{\Sigma} m_{q}^{\Delta}+4 i_{z}^{\Sigma} m_{Z d}^{\Delta} \\
i_{q}^{\Delta} m_{d}^{\Sigma}+2 i_{d}^{\Sigma} m_{q}^{\Delta}-i_{d}^{\Delta} m_{q}^{\Sigma}-2 i_{q}^{\Sigma} m_{d}^{\Delta}+4 i_{z}^{\Sigma} m_{Z q}^{\Delta}
\end{array}\right],
\end{aligned}
$$

$\mathbf{P}_{\omega_{0}}(t)$ denotes Park transformation at the angular frequency $\omega_{0}$, and $\mathbf{P}_{\omega_{0}}^{-1}(t)$ is the inverse Park transformation at the same frequency. It should be noted that all vectors are time-dependent. When translated to dqz-frame, AC side voltage is given as $v_{d}^{G}=V_{m} \cos (\theta)$ and $v_{q}^{G}=V_{m} \sin (\theta)$, where $V_{m}$ represents the amplitude and $\theta$ represents the phase shift. 
The model incorporates $d q z$-frames at the angular frequency $-2 \omega$ components for the $\Sigma$ variables and components at the frequencies $\omega$ and $3 \omega$ for $\Delta$ state variables, in accordance with [27]. The insertion indices $\overrightarrow{\boldsymbol{m}}=\left[\begin{array}{lll}\overrightarrow{\boldsymbol{m}}_{d q}^{\Delta} & \overrightarrow{\boldsymbol{m}}_{Z d q}^{\Delta} & \overrightarrow{\boldsymbol{m}}_{d q z}^{\Sigma}\end{array}\right]^{T}$ are obtained by using the following algebraic relation:

$$
\overrightarrow{\boldsymbol{m}}=\frac{2}{v_{d c}}\left[\begin{array}{c}
-\overrightarrow{\boldsymbol{v}}_{M}^{\Delta} \mathrm{MdqZ,ref} \\
\overrightarrow{\boldsymbol{v}}_{M d q z, r e f}^{\Sigma}
\end{array}\right] .
$$

This model appears to be suitable for both electromagnetic transient (EMT) and spectral simulation. Furthermore, it can be incorporated into a power flow simulator with the generalization of inner controlling loops [29]. One important fact is the model's suitability to implement various controlling methods [30].

In this work, the MMC operates as a grid forming converter and controls active and reactive power. We have analyzed two different control approaches-linear PI controller and nonlinear controller-using a combination of PI and sliding mode controllers, so called the integral sliding mode controller.

\subsection{Controller Implementations}

We have implemented a couple of inner and outer controlling loops. Inner controlling loops are depicted in Figure 3 and are all implemented as PI controllers. Inner controlling loops are controllers for controlling output current, circulating current, and zero current, see Figure 3. Parameters for the controllers from Figure $3 \mathrm{a}-\mathrm{c}$ are obtained using pole-zero placement algorithm. The outer controlling loop for the zero energy control is depicted in Figure 4.

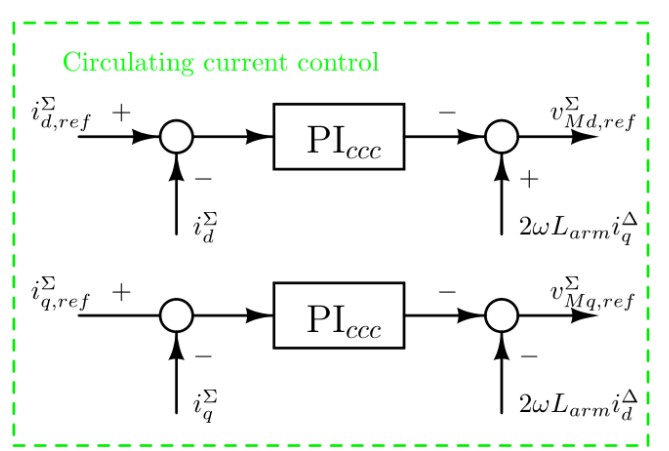

(a)

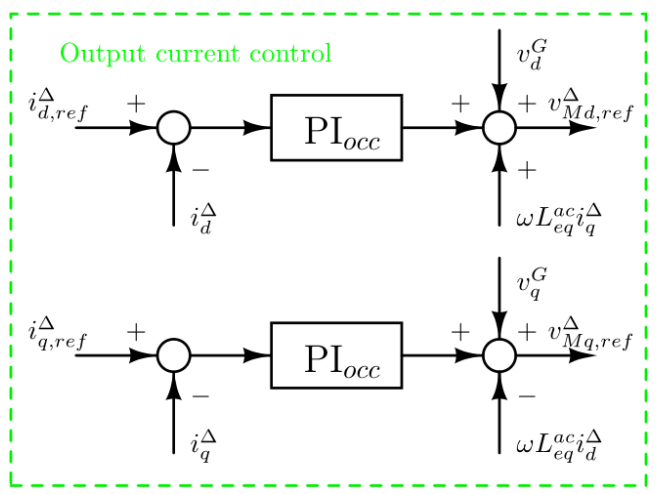

(b)

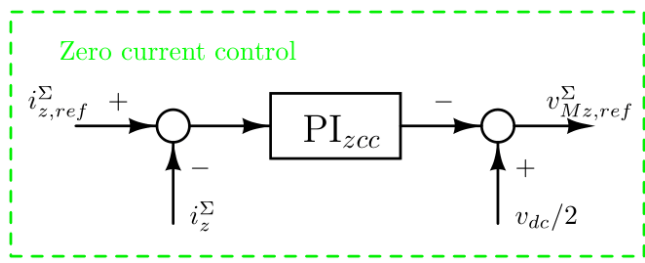

(c)

Figure 3. MMC's inner PI controlling loops for (a) circulating current, (b) output current, and (c) zero current.

In order to achieve stable zero current control reference, zero energy controller depicted in Figure 4 is used. It should be noted that the energy is calculated as

$$
W_{z}^{\Sigma}=\frac{3 C_{a r m}}{2 N}\left(v_{C d}^{\Delta}{ }^{2}+v_{C q}^{\Delta}{ }^{2}+v_{C Z d}^{\Delta}{ }^{2}+v_{C Z q}^{\Delta}{ }^{2}+v_{C d}^{\Sigma}{ }^{2}+v_{C q}^{\Sigma}{ }^{2}+2 v_{C z}^{\Sigma}{ }^{2}\right),
$$


the zero energy derivative is used to estimate reference for the current $i_{z}^{\Sigma}$ and, indirectly, to the great distinct it influences voltage $v_{\mathrm{C} z}^{\Sigma}$, which, in the case when the converter reaches its steady-state, has a value $v_{d c}$.

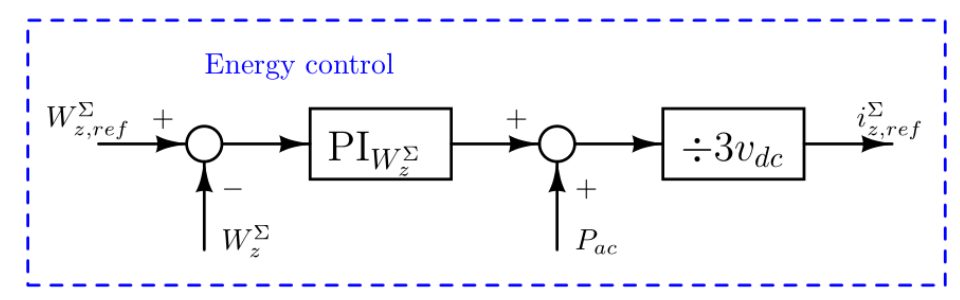

Figure 4. Energy controller.

\subsection{Active and Reactive Power Controllers}

Power control is suitable for the AC grid connected converters, since they have to provide sufficient active power to ensure good operation of the power system. Since we have tested the network identification algorithm and a response of an MMC to the load requirements, we have ensured that the converter provides the desired active and reactive power reference. The PI active and reactive power controller is depicted in Figure 5.

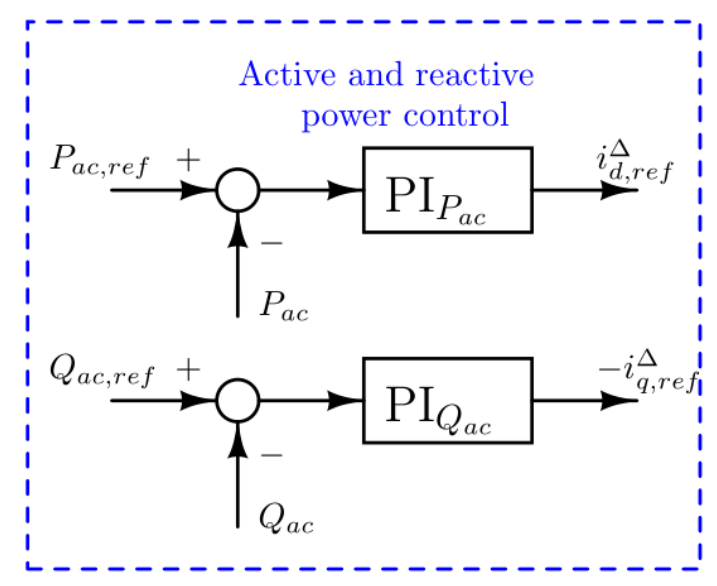

Figure 5. Active and reactive power PI controllers.

The active and reactive powers are given with the following formulas:

$$
\begin{aligned}
P_{a c} & =\frac{3}{2}\left(i_{d}^{\Delta} v_{d}^{G}+i_{q}^{\Delta} v_{q}^{G}\right), \\
Q_{a c} & =\frac{3}{2}\left(-i_{d}^{\Delta} v_{q}^{G}+i_{q}^{\Delta} v_{d}^{G}\right) .
\end{aligned}
$$

\subsection{Sliding Mode Control Design}

Sliding mode controller is defined as an extension of the output current controller. Thus, instead of using power controller from Figure 5 and output current controller from Figure $3 b$, the structure relies on the sliding surface, which is defined as an extended output current controller from Figure $3 b$. Namely, the integral sliding surface for the output current's $d$ or q component is defined as

$$
S\left(i_{d, q}^{\Delta}\right)=i_{d, q, r e f}^{\Delta}-i_{d, q}^{\Delta}
$$

and its time derivative as

$$
\dot{S}\left(i_{d, q}^{\Delta}\right)=-i_{d, q}^{\Delta}=-\sqrt{U} \sqrt{\left|x_{d, q}^{\Delta}\right|} \operatorname{sgn}\left(x_{d, q}^{\Delta}\right)-1.1 U x_{d, q}^{\Delta}
$$


with the positive constant $U$ and where $x_{d, q}$ are the corresponding outputs of the output current controller, defined as

$$
\begin{aligned}
& \dot{\vec{\xi}}_{d q}^{\Delta}=\overrightarrow{\boldsymbol{i}}_{d q, r e f}^{\Delta}-\overrightarrow{\boldsymbol{i}}_{d q}, \\
& \overrightarrow{\boldsymbol{x}}_{d q}^{\Delta}=K_{i}^{\Delta} \overrightarrow{\boldsymbol{\xi}}_{d q}+K_{p}^{\Delta} \dot{\overrightarrow{\boldsymbol{\xi}}}_{d q}^{\Delta} .
\end{aligned}
$$

Taking into account Equation (10a), the reference voltage is calculated as

$$
\left.\overrightarrow{\boldsymbol{v}}_{M d q}^{\Delta}=-L_{e q}^{a c} \dot{\overrightarrow{\boldsymbol{S}}}_{\left(\overrightarrow{\boldsymbol{i}}_{d q}\right.}^{\Delta}\right)+R_{e q}^{a c} \overrightarrow{\boldsymbol{i}}_{d q, r e f}^{\Delta}+\omega L_{e q}^{a c} \mathbf{J}_{2} \overrightarrow{\boldsymbol{i}}_{d q, r e f}^{\Delta}+\overrightarrow{\boldsymbol{v}}_{d q}^{G} .
$$

ISMC is a well-known sliding mode control method, and thus, the stability proof is avoided in the paper.

Output active power of HVDC in the case of ISMC and PI control when the reference value is set to $P_{a c}=-100 \mathrm{MW}$ is shown in Figure 6. It can be noticed that ISMC provides a faster response with smaller overshoot compared to PI control when it takes more than $0.2 \mathrm{~s}$ for output active power to reach reference value. Thus, application of ISMC is well justified.

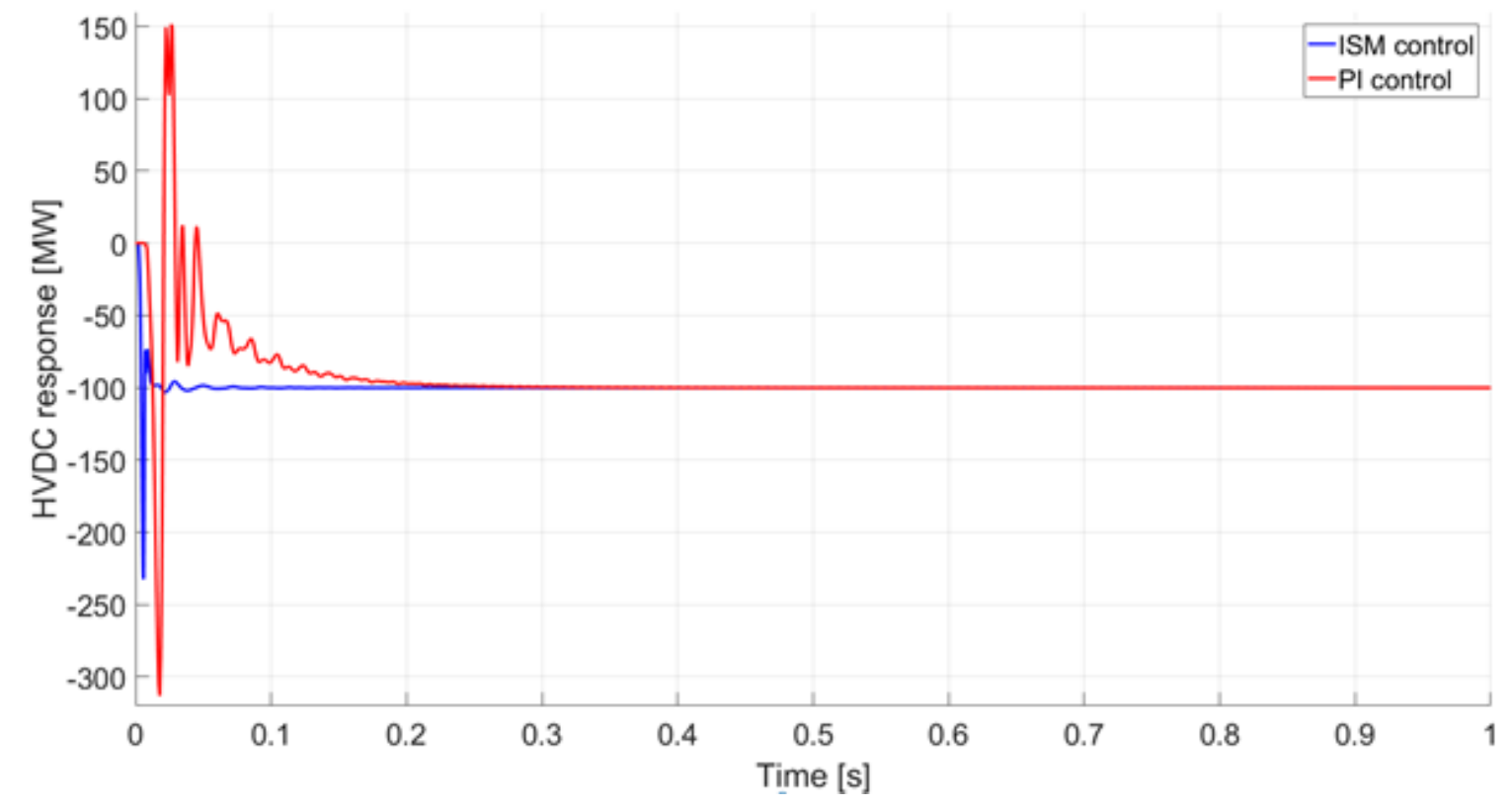

Figure 6. Output active power of HVDC in the case of integral sliding mode controller (ISMC) and PI control.

\section{Simulations}

Proposed HVDC control is validated by simulations on two configurations of the IEEE 39-bus power system (10-Machine New-England) modeled in MATLAB/Simulink for the original 10-synchronous machine IEEE 39-bus power system (see Figure 7a), and for an inertia-reduced 39-bus power system, it is created by replacing 3 synchronous generators with 3 wind power plants (see Figure 7b). On bus 39, an MMC is connected whose parameters are given in Table 1. Additionally, for the sliding mode controller parameter, $U=100$. 
Table 1. MMC parameters.

\begin{tabular}{cccccc}
\hline$N=50$ & $C_{a r m}=10 \mathrm{mF}$ & $L_{a r m}=50 \mathrm{mH}$ & $R_{a r m}=1.07 \Omega$ & $L_{r}=60 \mathrm{mH}$ & $R_{r}=0.535 \Omega$ \\
\hline$v_{d c}=200 \mathrm{kV}$ & $V_{m}=345 \sqrt{(2) \mathrm{kV}}$ & $\theta=0$ & & & \\
\hline$P I_{c c c}, P I_{z c c}$ & $K_{i}^{\Sigma}=8500$ & $K_{p}^{\Sigma}=19.93$ & $P I_{o c c}$ & $K_{i}^{\Delta}=85 \cdot 10^{3}$ & $K_{p}^{\Delta}=117.93$ \\
\hline$P I_{W_{z}^{\Sigma}}$ & $K_{i}^{W_{z}^{\Sigma}}=400$ & $K_{p}^{W_{z}^{\Sigma}}=120$ & $P I_{P_{a} c}, P I_{Q_{a} c}$ & $K_{i}^{P, Q}=6.67 \cdot 10^{-7}$ & $K_{p}^{P, Q}=3.33 \cdot 10^{-4}$ \\
\hline
\end{tabular}

Configuration I of the IEEE 39 bus test system from Figure 7a consists of ten generators represented as a six-order state-space model for the synchronous machine and includes a prime mover and an IEEE DC type 1 excitation system for automatic voltage regulation. Power plants have identical primary frequency controllers and fast static exciters. The generator model includes a primary frequency control with a static droop coefficient $R_{p}=5 \%$. The load is represented as constant power and it is independent on the frequency variations while the transmission lines are modeled as single PI sections.The generator G1, connected to bus 39, represents the aggregation of a large number of generators of the power system of New York that is interconnected with the New-England power system and represented in detail. Therefore, the HVDC interconnection link is also connected to bus 39 as it connects two power systems.

Configuration II of the test system (Figure $7 \mathrm{~b}$ ) is made from Configuration I by replacing 3 synchronous generators (G5, G8, and G9) with 3 wind plants (WP1, WP2, and WP3). The corresponding transformers are modified accordingly. The wind plants are modeled as aggregated type- 3 turbines and consist of DFIGs and averaged back-to-back converter models that preserve the dynamics resulting from the interaction between the control system and the power system. Wind power profiles are generated with $1 \mathrm{~s}$ resolution. More details of the two configurations of the IEEE 39 bus test system can be found in [31,32].
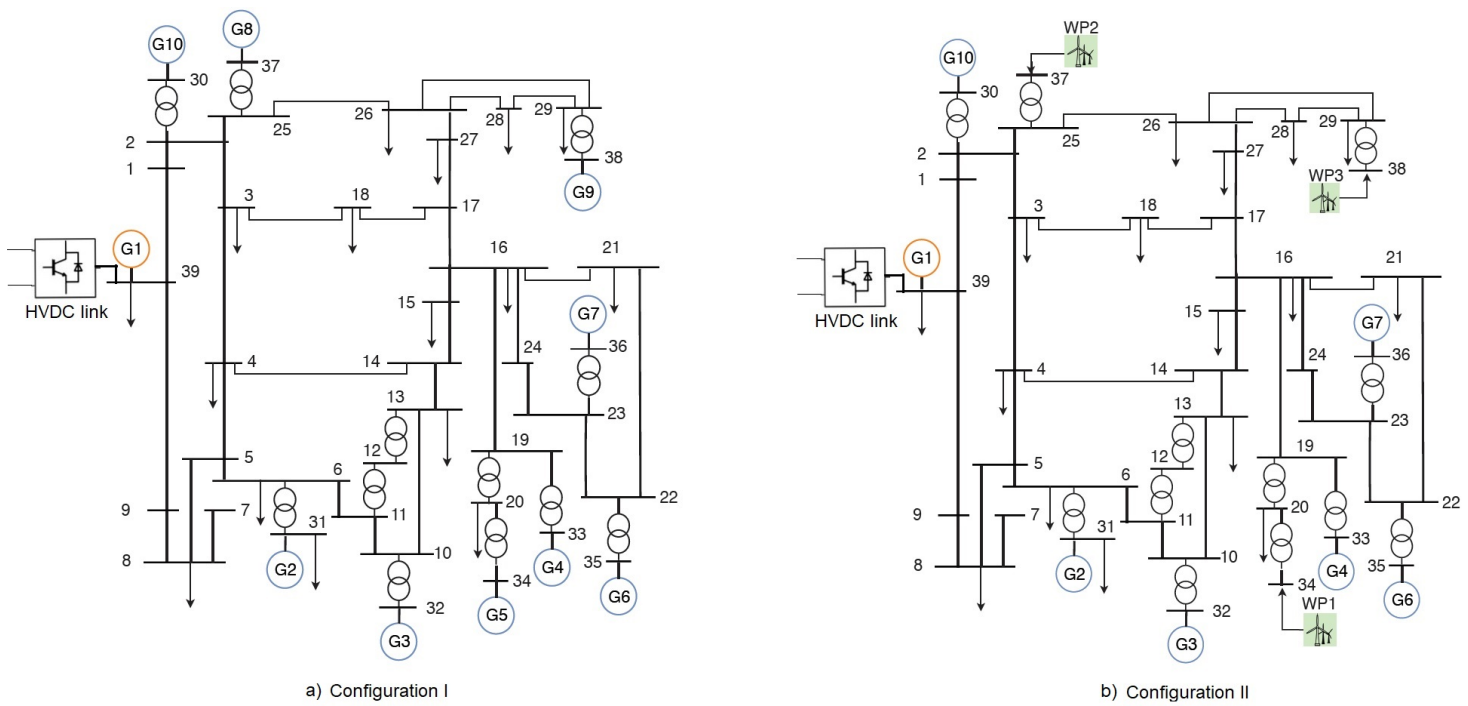

Figure 7. Configurations of the IEEE 39-bus dynamic power system.

The proposed HVDC control is validated on two configurations (original and the reduced inertia) of the IEEE 39 bus power system to demonstrate that the proposed control is not inertia-dependent and that it can be used in high-inertia as well as in low-inertia scenarios. For both configurations, the same two contingencies were tested to demonstrate that the proposed control is independent from the size of the disturbance and that it can estimate the size of the disturbance and provide adequate HVDC fast frequency response. The following simulations were conducted:

1. Configuration I-Big disturbance-the tripping of generator G6 that causes about $800 \mathrm{MW}$ of generation loss. 
2. Configuration II-Big disturbance- the tripping of generator G6 that causes about $800 \mathrm{MW}$ of generation loss.

3. Configuration I-Small disturbance-the tripping of generator G7 that causes about $450 \mathrm{MW}$ of generation loss.

4. Configuration II-Small disturbance-the tripping of generator G7 that causes about $450 \mathrm{MW}$ of generation loss.

For each simulation, three case scenarios were considered:

- $\quad$ No HVDC response (HVDC does not participate in frequency control).

- Nonadaptive (One-step) HVDC response (HVDC output active power is constant and independent from the size of disturbance and the system inertia).

- Adaptive (Two-step) HVDC response (HVDC output active power is adapted to the size of disturbance and the system inertia).

The initial output active power of the HVDC is $100 \mathrm{MW}$ and it is activated when the RoCoF is larger than a threshold value of $0.2 \mathrm{~Hz} / \mathrm{s}$ and the frequency is below $49.8 \mathrm{~Hz}$. It is taken that the first stage of HVDC response is dispatched $0.5 \mathrm{~s}$ after the disturbance and the second stage $0.5 \mathrm{~s}$ after the first one. The size of disturbance and adequate second step of HVDC response is calculated based on the frequency measurements obtained by PLL at bus 39 where HVDC is connected. Considering that the PLL will experience frequency spikes immediately after the disturbance that can affect punctuality of obtained frequency values, the calculation of the slope of the frequency response is done on the time interval from $0.2 \mathrm{~s}$ to $0.5 \mathrm{~s}$ after the disturbance. It is considered that $0.2 \mathrm{~s}$ after the disturbance/initial HVDC response frequency transients are negligible. It is taken that the critical frequency is below $49.2 \mathrm{~Hz}$ when the load shedding would be triggered, but it is not implemented in simulations.

Output active power of the HVDC in three scenarios for Simulation 1 in the case of sliding mode control and PI control is shown in Figure 8. Comparing the initial output active power of HVDC in the case of sliding mode control and PI control, it can be noticed that the HVDC response in the case of PI control is slower and takes more time to reach the specified reference value. This delay affects the accuracy of the estimated size of disturbance and gives a smaller value of the adaptive step of the HVDC response. The difference in output and reference value causes the miscalculation and gives the adaptive step that is undervalued. Consequently, the frequency goes below $49.2 \mathrm{~Hz}$ (Figure 9) and can trigger load shedding. In Figure 8, it is also visible that SMC-controlled MMC provides smaller overshoot of the power than PI controlled. With a one-step HVDC response, the output power is constant and has a value of $100 \mathrm{MW}$. In the case of adaptive control of HVDC, initial output power is equal to $100 \mathrm{MW}$ and the second step has a value of $205 \mathrm{MW}$ in case of sliding mode control; while with PI control, it is equal to $197 \mathrm{MW}$. The output power of the second step of HVDC response is smaller than the size of the disturbance because the aim of the fast frequency support from HVDC is not to establish power balance but to decelerate frequency decay and provide enough time for primary frequency control to restore load-generation balance. The output reactive power of HVDC is omitted on purpose since the HVDC barely feeds reactive power to the grid. This is because constant reactive power is given as a reference $\left(Q_{r e f}=0\right)$ to the controller, and the active and reactive power are controlled independently. Figure 9 represents the frequency measurements at bus 39, where the HVDC link that is produced by PLL is connected.

Figure 10 shows the generators' rotor speed after the tripping of generator G6 for configuration I of the test system. As can be seen from the figure, the frequency nadir for a case where there is no HVDC fast frequency response is significantly lower than the ones when HVDC provides a fast frequency response. With no HVDC response, the frequency goes below $49.2 \mathrm{~Hz}$ and would trigger undesirable load shedding in practice. Nonadaptive HVDC response enables better frequency nadir but is insufficient to limit frequency drop below the specified limit, while the adaptive one manages to keep the frequency above the specified minimum. In the case of one-step HVDC, control frequency reached $48.97 \mathrm{~Hz}$; and in the case of adaptive HVDC control, it reached $49.22 \mathrm{~Hz}$ and no load would 
be shed. This demonstrates the significant influence of the HVDC control on the transient frequency response of the power systems after the loss of generation.

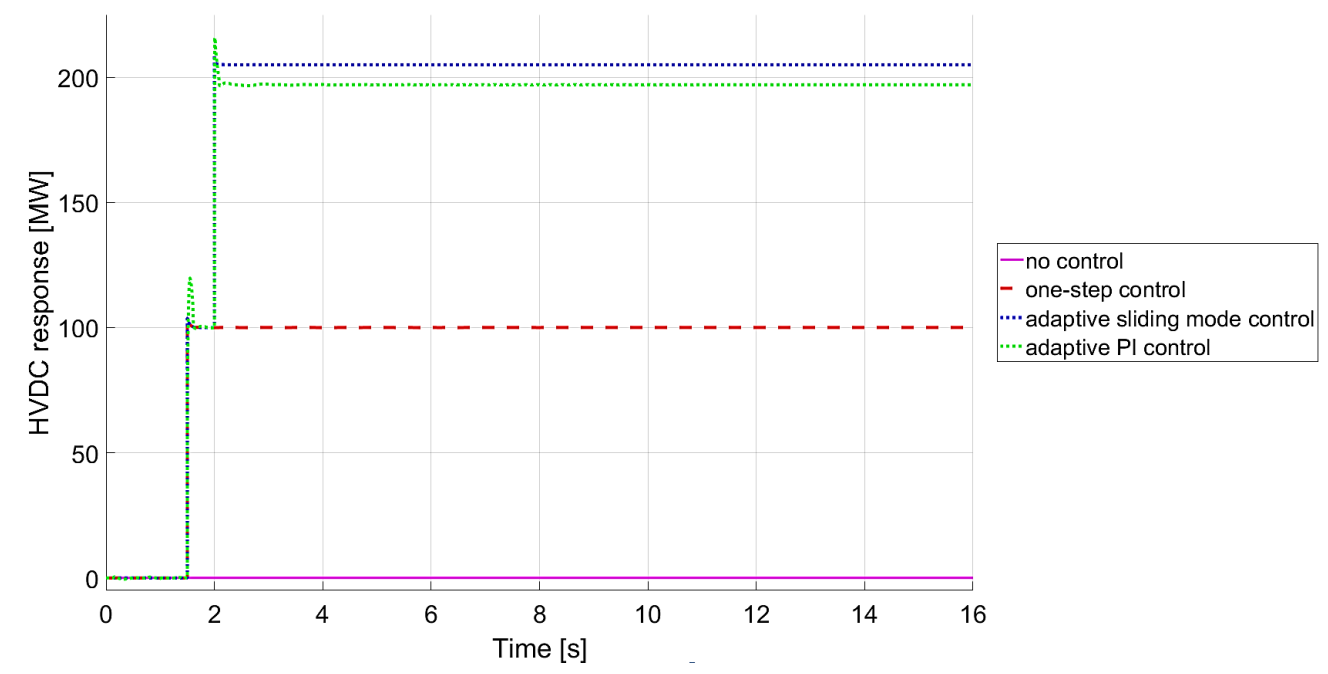

Figure 8. HVDC active power in Configuration I in case of big disturbance.

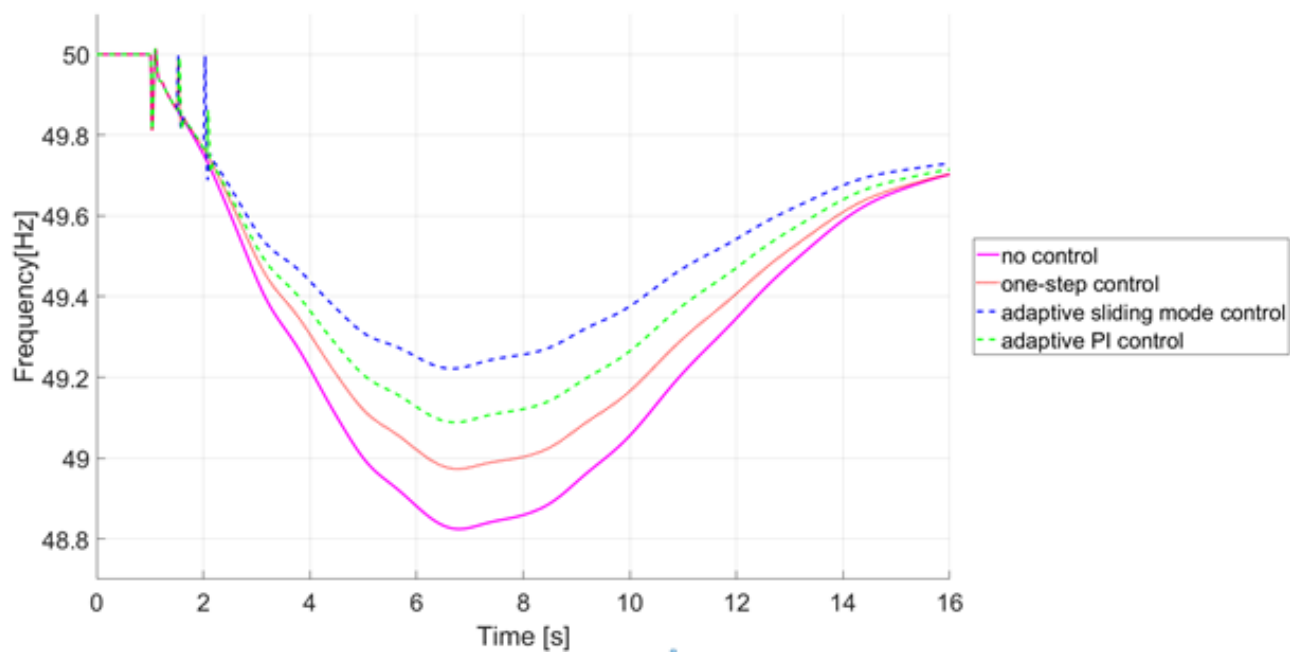

Figure 9. Frequency at bus 39 in Configuration I in case of big disturbance.

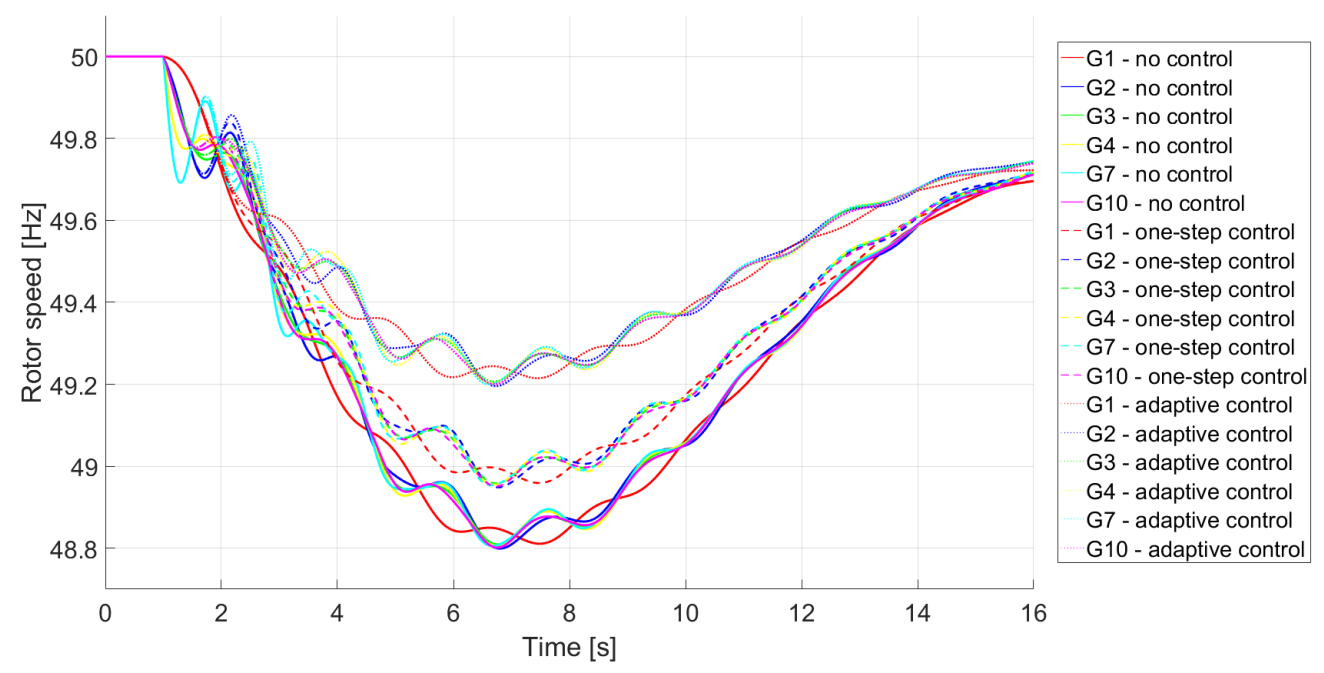

Figure 10. Generators' rotor speed in Configuration I in case of big disturbance. 
The same contingency from Simulation 1 is tested for Configuration II of the test system, i.e., the tripping of generator G6 that causes about $800 \mathrm{MW}$ of generation loss (Simulation 2). The output active power of the HVDC response in three scenarios for Simulation 2 in the case of sliding mode control and PI control is shown in Figure 11. Figure 12 represents the frequency measurements at bus 39 where the HVDC link that is produced by PLL is connected. With a one-step HVDC response, the output active power is constant and has a value of $100 \mathrm{MW}$. In the case of adaptive control of HVDC, initial output power is equal to $100 \mathrm{MW}$; while the second step has a value of $348 \mathrm{MW}$ in the case of sliding mode control and $334 \mathrm{MW}$ in the case of PI control. The delay introduced by PI control results in underestimation of the size of disturbance causing the smaller HVDC response, insufficient to maintain the frequency above $49.2 \mathrm{~Hz}$ (Figure 12). The output power of the second step of HVDC response in a low-inertia configuration is larger than the second step of HVDC response in high-inertia configuration that confirms that adaptive control considers the inertia of the test system. Generators' rotor speed responses in Simulation 2 are presented in Figure 13. Configuration II is low-inertia configuration and experience larger frequency decreasing velocity and magnitude compared to Configuration I for the disturbance of the same size. These results were expected since the low-inertia systems are more sensitive to disturbance. The frequency nadir for the case where there is no HVDC FFR response is below the threshold value of load shedding and it is equal to $48.67 \mathrm{~Hz}$. One-step HVDC response provides a higher frequency nadir equal to $48.83 \mathrm{~Hz}$, but it is below the threshold for load shedding. The two-step HVDC response gives frequency nadir equal to $49.2 \mathrm{~Hz}$ and keeps the frequency within safe boundaries. Simulation results confirm that the proposed HVDC control achieves adequate frequency response within the set limits in systems with different inertia levels while trying not to over-exploit the HVDC contribution. The adaptive step of HVDC response is proportional to the size of the estimated disturbance and initial RoCoF that is higher in low-inertia configuration compared to the same size disturbance in high-inertia configuration.

PI control introduces a delay that is neglected in the simple relations for adaptive control in Section 2. It should be noted that the delays are small but they are important in the FFR since they cause the error that results in insufficient response. ISMC allows better and faster HVDC response and enables efficient control of the frequency without endangering the stability of the HVDC. Therefore, ISMC is the only control implemented in Simulations 3 and 4.

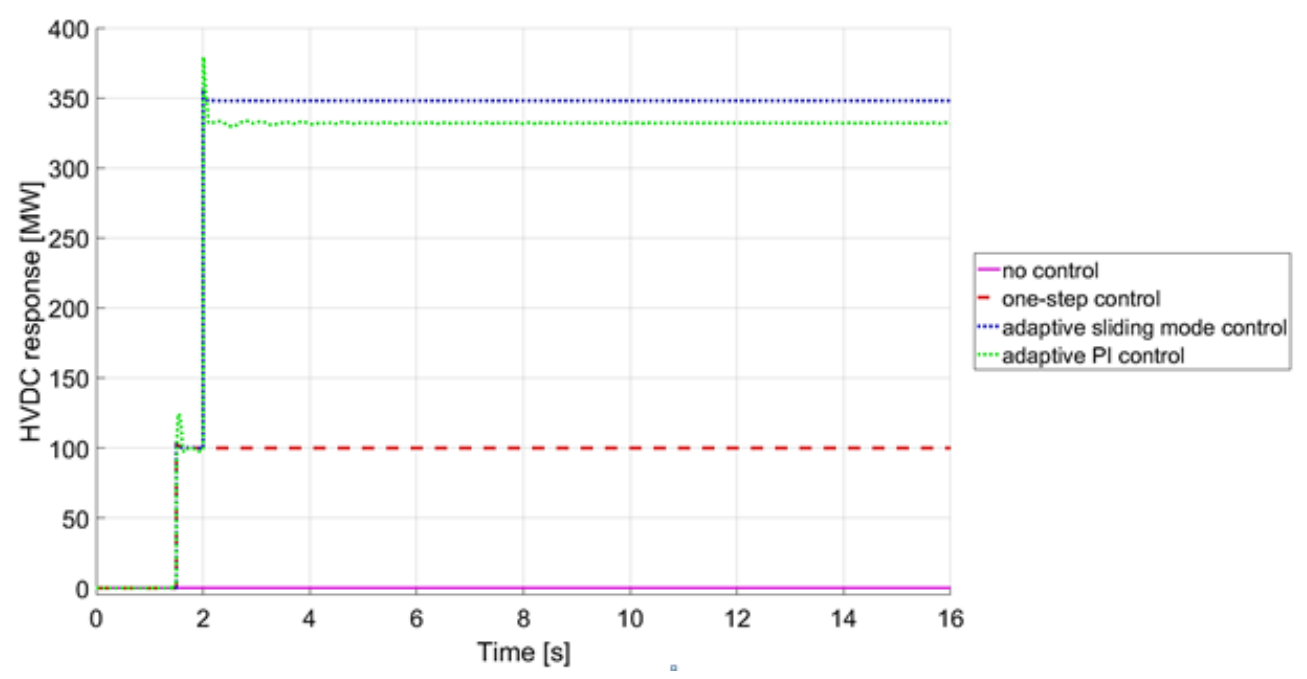

Figure 11. HVDC active power in Configuration II in case of big disturbance. 


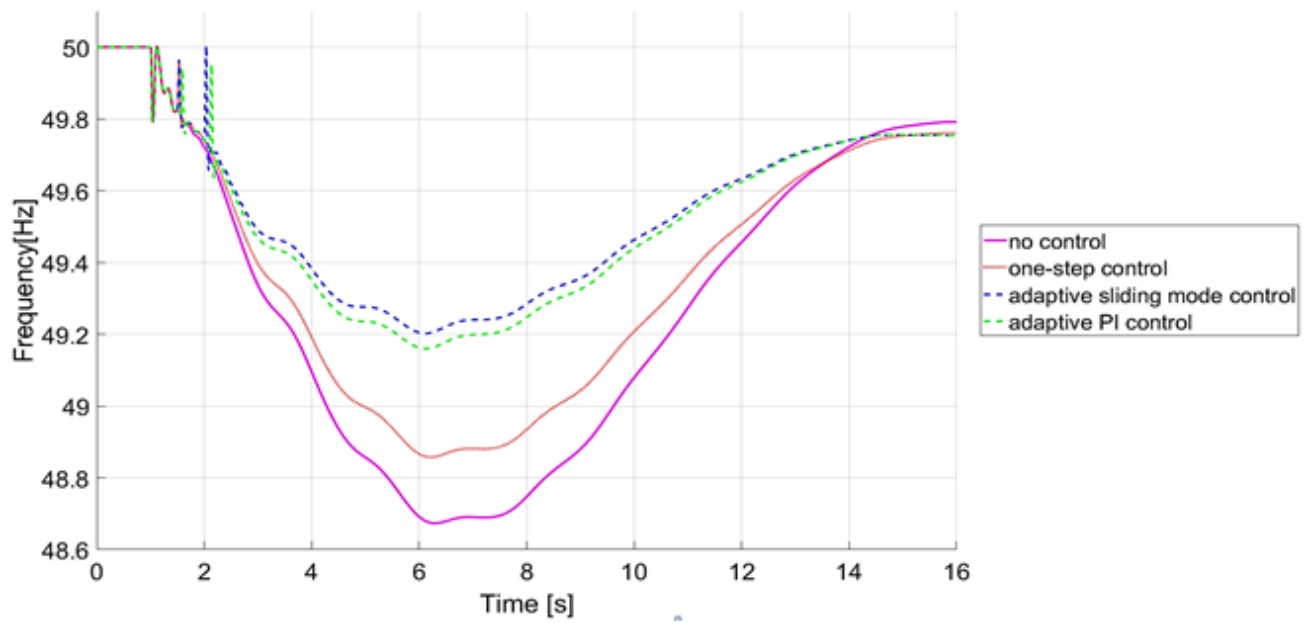

Figure 12. Frequency at bus 39 in Configuration II in case of big disturbance.

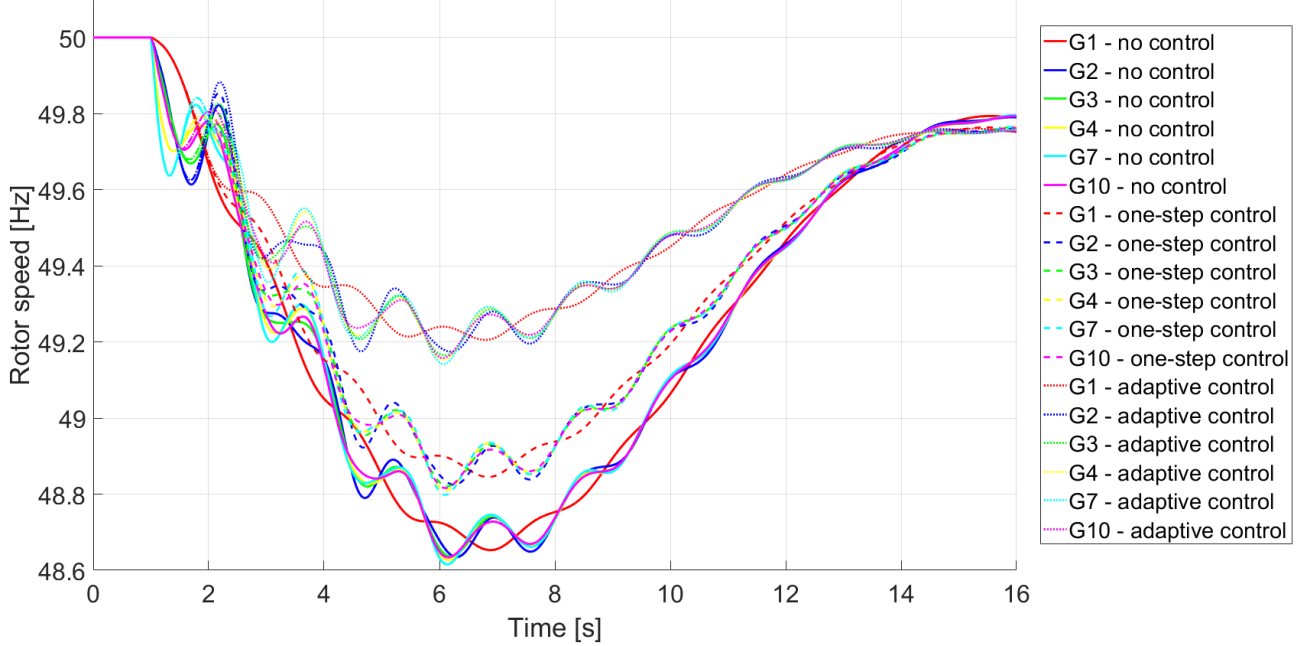

Figure 13. Generators' rotor speed in Configuration II in case of big disturbance.

Generators' rotor speed responses in the case of a small disturbance in the Configuration I of the test system are shown on Figure 14. The frequency nadir for the case where there is no HVDC FFR response is below the threshold value of load shedding and it is equal to $49.16 \mathrm{~Hz}$. One-step HVDC response provides a higher frequency nadir equal to $49.4 \mathrm{~Hz}$, which is above the threshold for load shedding. The two-step HVDC response gives lower frequency nadir compared to the one-step HVDC response but keeps the frequency within safe boundaries. Comparing the rotor speed curves for small disturbance in Configuration I (Simulation 3) with those for big disturbance in Configuration I (Simulation 1), it can be noticed that smaller disturbance results in a slower frequency decay and a higher frequency nadir which is expected. Figure 15 represents the frequency measurements at bus 39, where the HVDC link that is produced by PLL is connected. Output active power of the HVDC response in three scenarios for Simulation 3 is shown in Figure 16. With a one-step HVDC response, the output power is constant and has a value of $100 \mathrm{MW}$; while in the case of adaptive control of HVDC, initial output power is equal to $100 \mathrm{MW}$ and the second step has a value of $95 \mathrm{MW}$. The output power of the second step of HVDC is smaller than the first one since the initial response is bigger than needed and the frequency stability would not be endangered if the smaller amount of FFR reserve is dispatched. This way, adaptive control of HVDC enables a more cost-efficient solution, releasing a part of FFR reserve without compromising frequency stability. Comparing the ration of the output power of the second step of HVDC response and the size of disturbance, it can be noticed that for the same configuration and power system inertia, the ratio is larger for a larger disturbance. This is due 
to the fact that the adaptive step is proportional to the size of the estimated disturbance and initial RoCoF value which is bigger in the case of bigger disturbance.

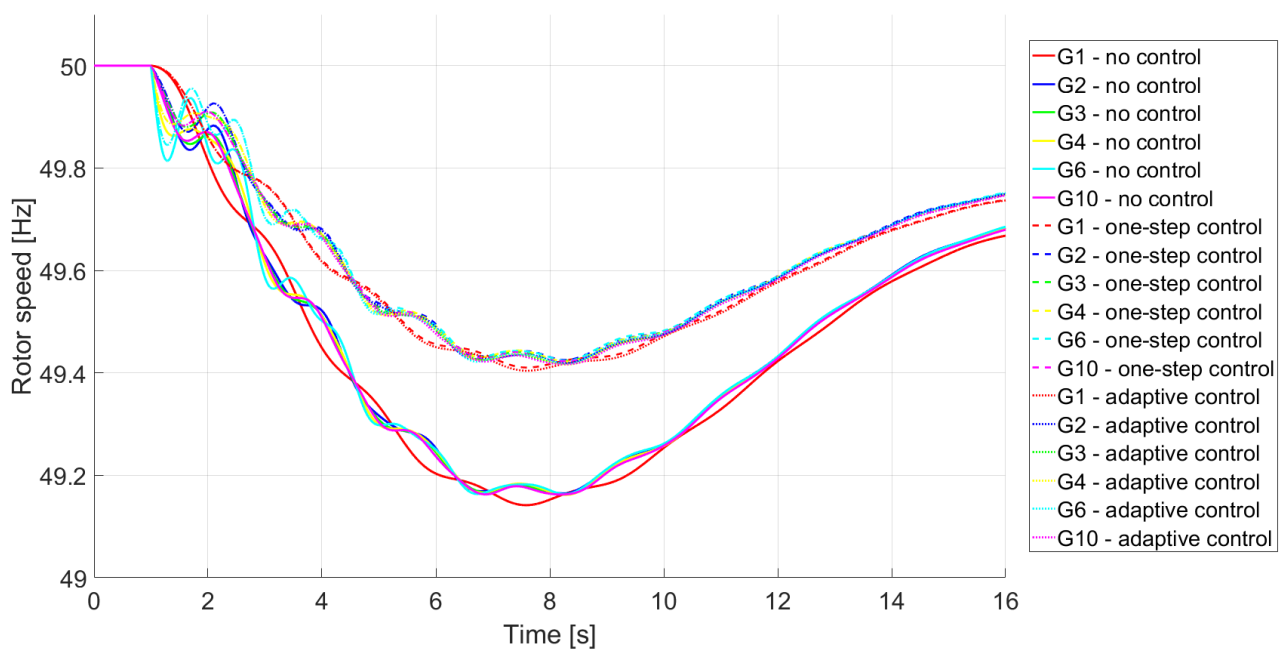

Figure 14. Generators' rotor speed in Configuration I in case of small disturbance.

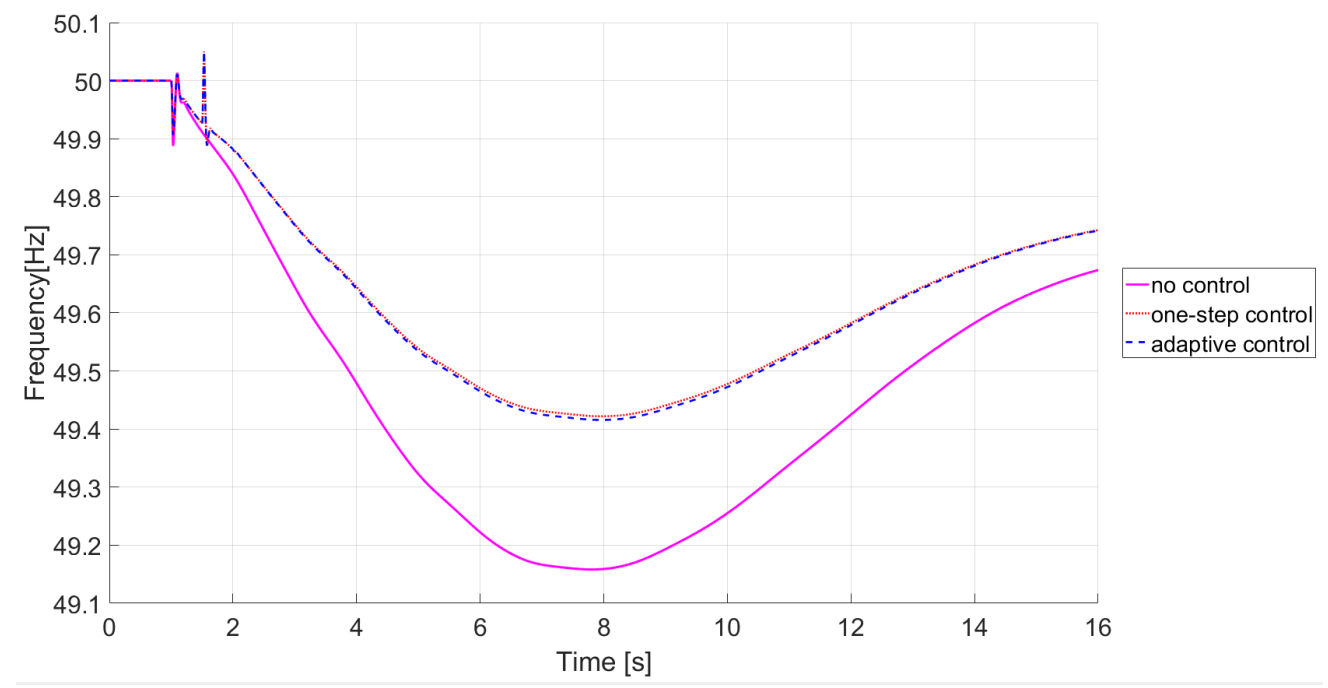

Figure 15. Frequency at bus 39 in Configuration I in case of small disturbance.

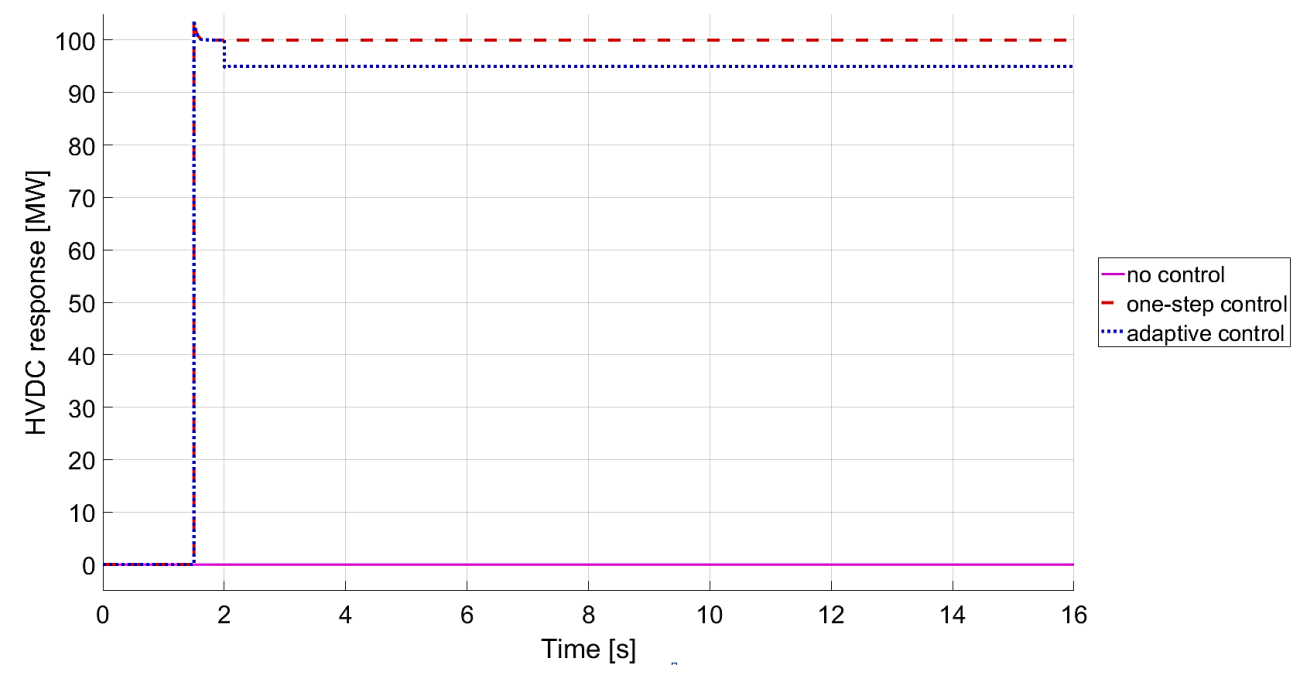

Figure 16. HVDC active power in Configuration I in case of small disturbance. 
The same contingency from Simulation 3 is tested for Configuration II of the test system, i.e., the tripping of generator G7 that causes about $450 \mathrm{MW}$ of generation loss (Simulation 4). Generators' rotor speed responses in Simulation 4 are presented in Figure 17. Configuration II is low -inertia configuration and experience larger frequency decreasing velocity and magnitude compared to Configuration I for the disturbance of the same size. These results were expected since the low-inertia systems are more sensitive to disturbance. The frequency nadir for the case where there is no HVDC FFR response is below the threshold value of load shedding and is equal to $49 \mathrm{~Hz}$. One-step HVDC response provides a higher frequency nadir equal to $49.17 \mathrm{~Hz}$, but is below the threshold for load shedding. The two-step HVDC response gives frequency nadir equal to $49.24 \mathrm{~Hz}$ and keeps the frequency within safe boundaries. Figure 18 represents the frequency measurements at bus 39, where the HVDC link is connected that is produced by PLL. Output active power of the HVDC response in three scenarios for the Simulation 2 is shown in Figure 19. With a one-step HVDC response, the output active power is constant and has a value of $100 \mathrm{MW}$; while in the case of adaptive control of HVDC initial output power is equal to $100 \mathrm{MW}$ and the second step has a value of $151 \mathrm{MW}$. The output power of the second step of HVDC response in low-inertia configuration is larger than the second step of HVDC response in high-inertia configuration for the same disturbance that confirms that adaptive control considers the inertia of the test system. The adaptive step of HVDC response is proportional to the size of the estimated disturbance and initial RoCoF that is higher in low-inertia configuration compared to the same size disturbance in high-inertia configuration.

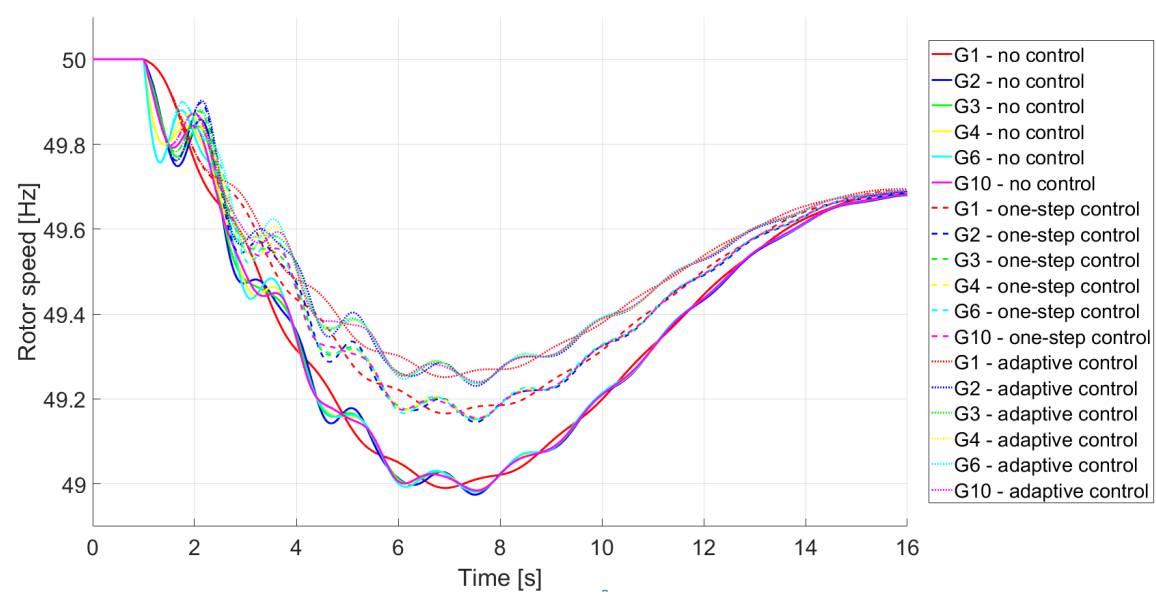

Figure 17. Generators' rotor speed in Configuration II in case of small disturbance.

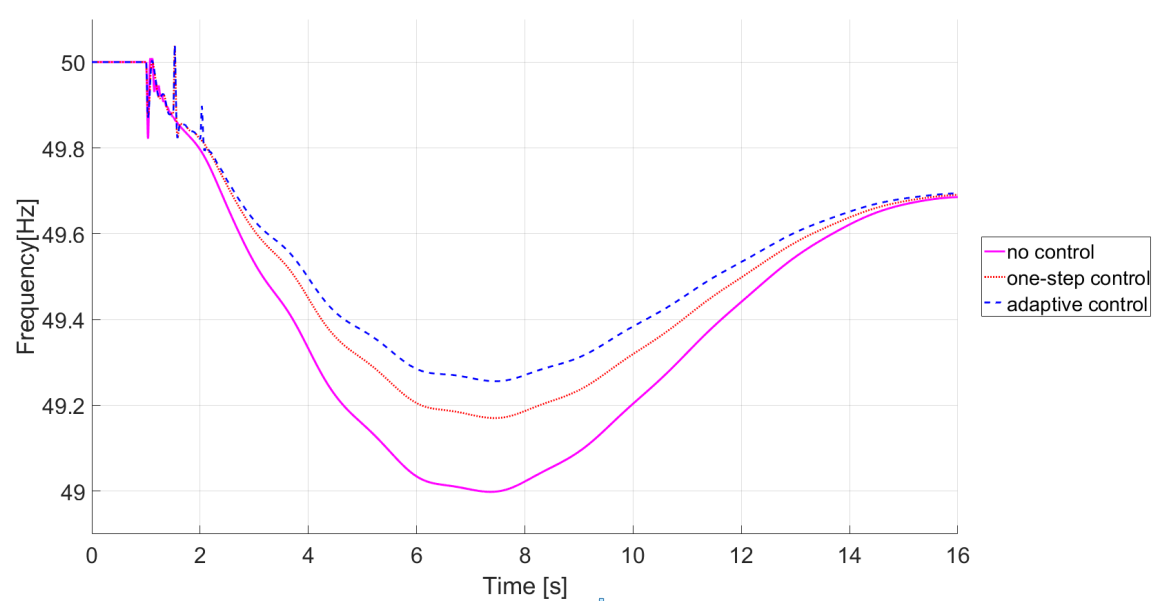

Figure 18. Frequency at bus 39 in Configuration II in case of small disturbance. 


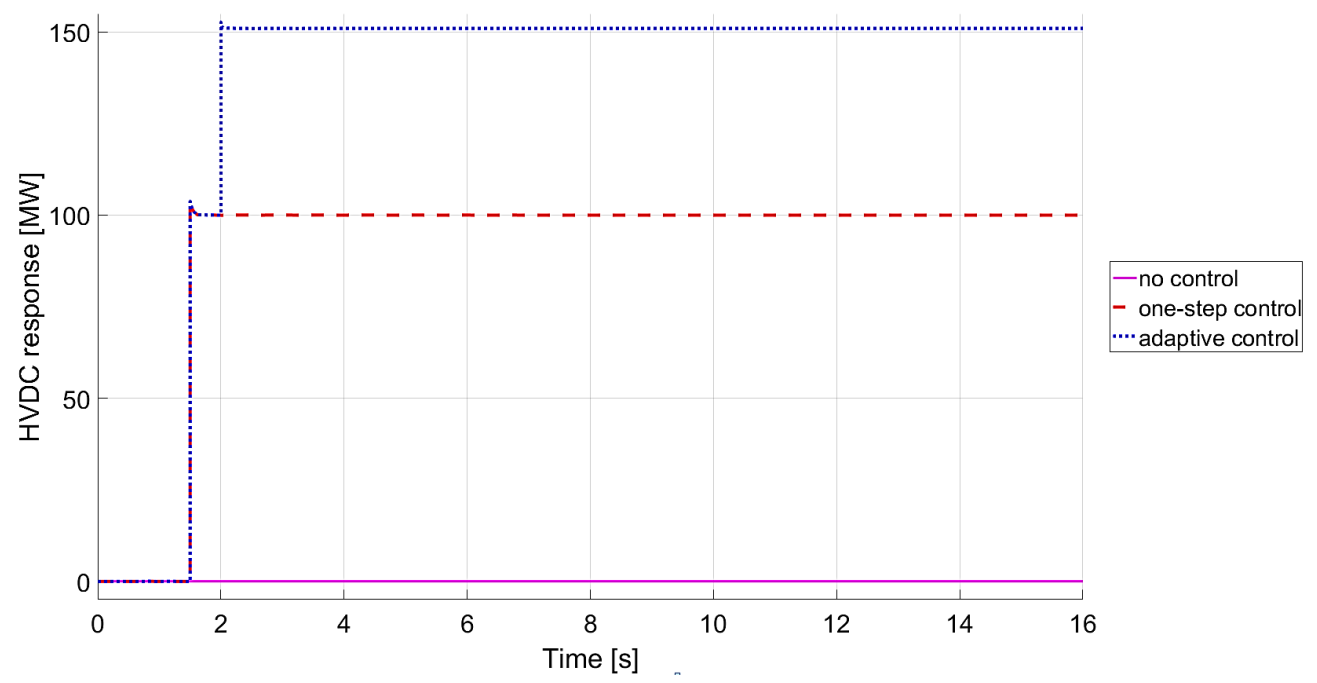

Figure 19. Frequency at bus 39 in Configuration II in case of small disturbance.

\section{Conclusions}

This paper proposes the adaptive control of the HVDC link for frequency stability enhancement in low-inertia systems. HVDC links can provide fast frequency support, and therefore present a valuable tool in a low-inertia system that is particularly sensitive to disturbance in terms of frequency stability. The frequency change is fast, and the conventional primary frequency control is not fast enough to preserve frequency above specified limits. The proposed HVDC control aims to maintain frequency within safe limits and prevent load shedding. The proposed adaptive control consists of two stages. The initial stage of the HVDC response is dispatched when the RoCoF value goes above the specified threshold. The value of the RoCoF threshold should be selected carefully to detect potentially dangerous disturbance. The second stage of the HVDC response is calculated based on the change of frequency response after the initial HVDC response. The second stage of HVDC control aims to estimate the size disturbance and provide an adequate response that will keep frequency within safe boundaries. This way, the proposed control is independent of the size of disturbance and the system inertia. PI control of MMC introduces a delay in HVDC response and creates an error in the disturbance estimation, consequently leading to insufficient HVDC response in the second step. Therefore, an integral sliding mode control of MMC that provides faster response is developed and implemented in the simulations, which confirms that the proposed control strategy successfully exploits the fast dynamics of HVDC converters and verifies the applicability of the proposed method. The performance of the proposed adaptive controller is verified by simulations in MATLAB/Simulink and tested for different sizes of disturbance and different inertias of the power system. Performed simulations verify that the proposed adaptive control of HVDC manages to keep frequency above a specified limit and provides better frequency response compared to one-step control. The results of the simulations confirm that the proposed control provides a suitable response for different sizes of disturbance and different values of system inertia. Future work would focus on the coordination of the FFR with the traditional primary frequency control. The adaptive FFR control model could be extended to enable a more adequate response taking into account primary controllers and the responses of other electronic devices. In addition, the value of the RoCoF threshold will be carefully investigated so the HVDC fast frequency response would not be triggered for a noncritical disturbance.

Author Contributions: Conceptualization, methodology, formal analysis: J.S. and A.L.; writing-original draft preparation: J.S., A.L., and P.S.; idea, supervision: P.S. All authors have read and agreed to the published version of the manuscript.

Funding: This research received no external funding.

Conflicts of Interest: The authors declare no conflict of interest. 


\section{References}

1. Steve, S.; Nemanja, K.; Soon, K.Y.; David, H. All Island TSO Facilitation of Renewables Studies; Technical Report; EirGrid and SONI: Dublin, Ireland, 2009.

2. Ensuring a Secure, Reliable and Efficient Power System in a Changing Environment; Technical Report; EirGrid and SONI: Dublin, Ireland, 2011. Available online: http://www.eirgridgroup.com/site-files/library/EirGrid/ Ensuring-a-Secure-Reliable-and-Efficient-Power-System-Report.pdf (accessed on 22 November 2020).

3. House, N.G. System Operability Framework; Technical Report; UK Electricity Transmission: London, UK, November 2016.

4. House, N.G. Enhanced Frequency Response; Technical Report; UK Electricity Transmission: London, UK, 2016.

5. House, N.G. Technical Report on the Events of 9 August 2019; Technical Report; UK Electricity Transmission: London, UK, 2019.

6. Kaushal, A.; Van Hertem, D. An Overview of Ancillary Services and HVDC Systems in European Context. Energies 2019, 12, 3481. [CrossRef]

7. Jallad, J.; Mekhilef, S.; Mokhlis, H. Frequency regulation strategies in grid integrated offshore wind turbines via VSC-HVDC technology: A review. Energies 2017, 10, 1244. [CrossRef]

8. Yu, M.; Dyśko, A.; Booth, C.D.; Roscoe, A.J.; Zhu, J. A review of control methods for providing frequency response in VSC-HVDC transmission systems. In Proceedings of the 2014 49th International Universities Power Engineering Conference (UPEC), Cluj-Napoca, Romania, 2-5 September 2014; pp. 1-6.

9. Luo, P.-D.; Yuan, Z.-C.; Sheng, C.; Zhu, L.-H.; Yang, F.-Y. Review of frequency support control strategies for asynchronous AC systems connected through VSC-HVDC. In Proceedings of the 2nd International Conference on Energy, Power and Electrical Engineering (EPEE 2017), Chongqing, China, 23-25 April 2017; pp. 414-421.

10. Dijokas, M.; Tosatto, A.; Weckesser, T.; Chatzivasileiadis, S.; Eriksson, R. Sharing reserves through HVDC: potential cost savings in the Nordic countries. arXiv 2020, arXiv:2001.00664.

11. Sun, K.; Li, K.J.; Pan, J.; Xiao, H.; Liu, Y. Frequency Response Reserves Sharing through VSC-HVDC for Interconnections. In Proceedings of the 2019 IEEE Power \& Energy Society General Meeting (PESGM), Atlanta, GA, USA, 4-8 August 2019; pp. 1-5.

12. Huang, J.; Preece, R. HVDC-based fast frequency support for low inertia power systems. In Proceedings of the 13th IET International Conference on AC and DC Power Transmission (ACDC 2017), Manchester, UK, 14-16 February 2017; pp. 1-6.

13. De Haan, J.E.; Concha, C.E.; Gibescu, M.; van Putten, J.; Doorman, G.L.; Kling, W.L. Stabilising system frequency using HVDC between the Continental European, Nordic, and Great Britain systems. Sustain. Energy Grids Netw. 2016, 5, 125-134. [CrossRef]

14. Shen, L.; Barnes, M.; Preece, R.; Milanović, J. Frequency stabilisation using VSC-HVDC. In Proceedings of the 2016 IEEE Power and Energy Society General Meeting (PESGM), Boston, MA, USA, 17-21 July 2016; pp. 1-5.

15. Lee, G.; Moon, S.; Hwang, P. A Frequency-Power Droop Coefficient Determination Method of Mixed Line-Commutated and Voltage-Sourced Converter Multi-Infeed, High-Voltage, Direct Current Systems: An Actual Case Study in Korea. Appl. Sci. 2019, 9, 606. [CrossRef]

16. Wang, H.; Wang, Y.; Duan, G.; Hu, W.; Wang, W.; Chen, Z. An improved droop control method for multi-terminal VSC-HVDC converter stations. Energies 2017, 10, 843. [CrossRef]

17. Obradovic, D.; Dijokas, M.; Van Cutsem, T.; Eriksson, R.; Ghandhari, M.; Tosatto, A. Assessment of HVDC Frequency Control Methods in the Nordic Test System. In Proceedings of the CIGRE 2020 Conference, Paris, France, 24 August-3 September 2020.

18. Haro-Larrode, M.; Santos-Mugica, M.; Etxegarai, A.; Eguia, P. Methodology for Tuning MTDC Supervisory and Frequency-Response Control Systems at Terminal Level under Over-Frequency Events. Energies 2020, 13, 2807. [CrossRef]

19. Sharifabadi, K.; Harnefors, L.; Nee, H.P.; Norrga, S.; Teodorescu, R. Design, Control, and Application of Modular Multilevel Converters for HVDC Transmission Systems; John Wiley \& Sons: Hoboken, NJ, UAS, 2016.

20. Du, S.; Dekka, A.; Wu, B.; Zargari, N. Modular Multilevel Converters: Analysis, Control, and Applications; John Wiley \& Sons: Hoboken, NJ, UAS, 2017. 
21. Da Silva, G.S.; Vieira, R.P.; Rech, C. Discrete-Time Sliding-Mode Observer for Capacitor Voltage Control in Modular Multilevel Converters. IEEE Trans. Ind. Electron. 2018, 65, 876-886. [CrossRef]

22. Uddin, W.; Zeb, K.; Adil Khan, M.; Ishfaq, M.; Khan, I.; Kim, H.J.; Park, G.S.; Lee, C. Control of Output and Circulating Current of Modular Multilevel Converter Using a Sliding Mode Approach. Energies 2019, 12, 4084. [CrossRef]

23. Yang, X.; Li, Z.; Zheng, T.Q.; You, X.; Kobrle, P. Virtual Impedance Sliding Mode Control-Based MMC Circulating Current Suppressing Strategy. IEEE Access 2019, 7, 26229-26240. [CrossRef]

24. Westman, M.; Nordén, E. Modeling and Comparative Analysis of Different Grid-Forming Converter Control Concepts for Very Low Inertia Systems. 2020. Available online: http:/ / www.diva-portal.org/smash/record. jsf?pid=diva2:1446840 (accessed on 22 November 2020).

25. Tian, S.; Campos-Gaona, D.; A Lacerda, V.; Torres-Olguin, R.E.; Anaya-Lara, O. Novel control approach for a hybrid grid-forming HVDC offshore transmission system. Energies 2020, 13, 1681. [CrossRef]

26. Unruh, P.; Nuschke, M.; Strauß, P.; Welck, F. Overview on Grid-Forming Inverter Control Methods. Energies 2020, 13, 2589. [CrossRef]

27. Bergna-Diaz, G.; Freytes, J.; Guillaud, X.; D'Arco, S.; Suul, J.A. Generalized Voltage-Based State-Space Modeling of Modular Multilevel Converters With Constant Equilibrium in Steady State. IEEE J. Emerg. Sel. Top. Power Electron. 2018, 6, 707-725. [CrossRef]

28. Freytes, J. Small-Signal Stability Analysis of Modular Multilevel Converters and Application to MMC-Based Multi-Terminal DC Grids. Ph.D. Thesis, Dept. Laboratoire L2ep, Ecole Centrale de Lille, Villeneuved'Ascq, France, 2017.

29. Lekić, A.; Ergun, H.; Beerten, J. Initialisation of a hybrid AC/DC power system for harmonic stability analysis using a power flow formulation. High Voltage 2020, 5, 534-542. [CrossRef]

30. Bergna-Diaz, G.; Zonetti, D.; Sanchez, S.; Ortega, R.; Tedeschi, E. PI Passivity-Based Control and Performance Analysis of MMC Multiterminal HVDC Systems. IEEE J. Emerg. Sel. Top. Power Electron. 2019, 7, 2453-2466. [CrossRef]

31. Canizares, C.; Fernandes, T.; Geraldi, E., Jr.; Gérin-Lajoie, L.; Gibbard, M.; Hiskens, I.; Kersulis, J.; Kuiava, R.; Lima, L.; Marco, F.; et al. Benchmark Systems for Small Signal Stability Analysis and Control. 2015. Available online: http:/ / resourcecenter.ieee-pes.org/pes/product/technical-reports/PESTR18 (accessed on 22 November 2020).

32. Derviškadić, A.; Zuo, Y.; Frigo, G.; Paolone, M. Under frequency load shedding based on PMU estimates of frequency and ROCOF. In Proceedings of the 2018 IEEE PES Innovative Smart Grid Technologies Conference Europe (ISGT-Europe), Sarajevo, Bosnia and Herzegovina, 21-25 October 2018; pp. 1-6.

Publisher's Note: MDPI stays neutral with regard to jurisdictional claims in published maps and institutional affiliations.

(C) 2020 by the authors. Licensee MDPI, Basel, Switzerland. This article is an open access article distributed under the terms and conditions of the Creative Commons Attribution (CC BY) license (http:// creativecommons.org/licenses/by/4.0/). 